\title{
Combination of Fuels for Improved Thrust
}

[Vijaya Bharathi Kandasamy, Ramkumar Neralur Prabhu, Karthik Sharma Tumuluri, Aditya Annavaram]

\begin{abstract}
Fuel is one of the research areas of major focus in recent days. This review paper is based on the principle that it may be possible to grow our way out of an energy crisis with renewable, recyclable plant-based fuels. In turbine aircraft, combustion process acts on fan blades that either turns a propeller or create thrust by accelerating gas. The fuel used is jet fuel (jet-A, jet-1A, jet-B). Biofuels have to replicate the characteristics of jet fuels in order to place a claim as future aviation fuel. The biggest challenge is to find out a renewable fuel which fits the bill. One such biofuel in the race is the $3^{\text {rd }}$ generation 'algae'. There are few technical and legal issues in using algae for production of biofuel and they are: Technical issues: Diesel fuel stability (extremely high flash point and low volatility), Fuel freezing point temperature, Lack of lubricity, Low energy density. Legal issues: Renewable fuel standard, Clean air act, Toxic substance control act, Clean water act, Plant protection act, National environmental policy act, Endangered species act. The biofuels have to overcome these issues and be accepted by respective regulatory bodies. Use of biofuels can reduce CO2 emission by up to $80 \%$ over their full cycle. Since algae consume $\mathrm{CO} 2$ while growing, it provides mitigation benefits on $\mathrm{CO} 2$. On studying algae growth, it has been found that the properties of algae vary depending on the fertilizers used to feed them. Using the turbine code in MATLAB, the calorific value of halophytic algae is analyzed and compared with jet fuel and the graph (thermal and propeller efficiency versus compression ratio) is plotted to study their performance. This paper is about $1^{\text {st }}$ phase of the research. From the results obtained it is observed that the halophytic algae have better performance compared to conventional jet fuel.
\end{abstract}

Keywords- Biofuel, halophytic algae, MATLAB, carbon dioxide emission.
Vijaya Bharathi Kandasamy

Brunel University London

Karthik Sharma Tumuluri Brunel University London
Ramkumar Neralur Prabhu Brunel University London

Aditya Annavaram Brunel University London

\section{Abbreviations}

1) $P_{\text {to }}$-Total pressure at inlet conditions

2) $\mathrm{P}_{0}-$ Air pressure and altitude above sea level.

3) $\mathrm{K}_{\mathrm{c}}$ - Cold section only
4) $T_{\text {to }}$ - Total pressure at inlet condition

5) $T_{0}-$ Temperature at inlet conditions

6) TaoR and TaoC-Compressor pressure ratio

7) QR -Calorific value.

8) $n_{t}$-Turbine adiabatic efficiency

9) $n_{m}$-Mechanical efficiency

10) $f$-fuel air ratio

11) $\mathrm{N}_{\mathrm{c}}$-Compressor efficiency

12) $P_{t}-$ Total pressure

13) $m_{0}$ - Mass flow

14) $o_{f}-$ Fuel flow rate

15) $V_{o}$ - Speed at initial conditions

16) $V_{9}$-Speed at nozzle

17) F -Uninstalled thrust

\section{INTRODUCTION}

Use of alternate fuel to reduce the cost and maintenance has been one of the majorly concentrated domains (in recent days) in the aviation industry. Fuel efficiency depends on various aspects like material selection, type of fuel and other factors. This paper mainly concentrates on increasing the efficiency of fuel with environment as the major factor, while also concentrating on reduced cost as compared to conventional fuel presently used in the aviation industry. Conventional fuels which are currently being used are releasing GHG gases. The figure given below represents the life cycle $\mathrm{CO} 2$ emissions versus year as a percent of 2005 level (Anon., 2015).

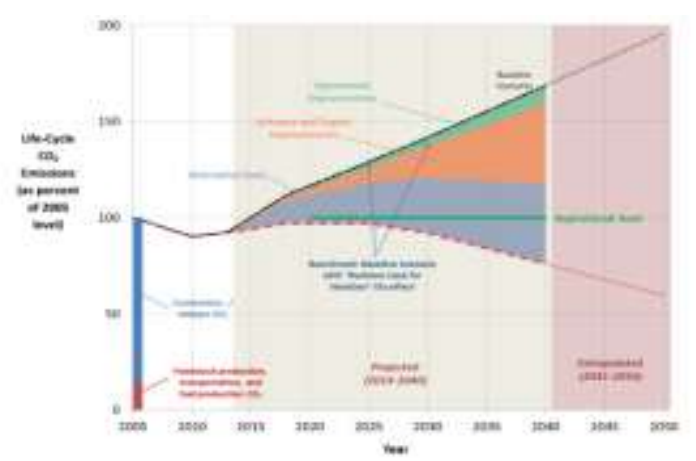

Fig. 1 (Anon., 2015)

Fuels are being replaced by alternate fuels because of following reasons: 
- Increase in demand of world's petroleum resources.

- Greenhouse gas emissions.

Besides price, other factors which must be taken into account when considering alternative fuels are - safe and reliable operations of the engine without compromising the performance of aircraft. The environmental effects of alternative fuel must also be considered as an important factor (Greg Hemighaus, 2006). This includes emissions from the engine and life-cycle effects associated with production and use of alternative fuels. Cryogenic fuels such as liquid hydrogen and other more exotic fuels such as boron compounds were studied in 1950's and 1960's. The research on alternative fuels gained pace after 1973 US energy crises when fuel prices increased dramatically (Greg Hemighaus, 2006).

The jet fuel consumption in 2003 was about 190million gallons per day. The properties of the conventional fuels used are as given in the table below (Greg Hemighaus, 2006).

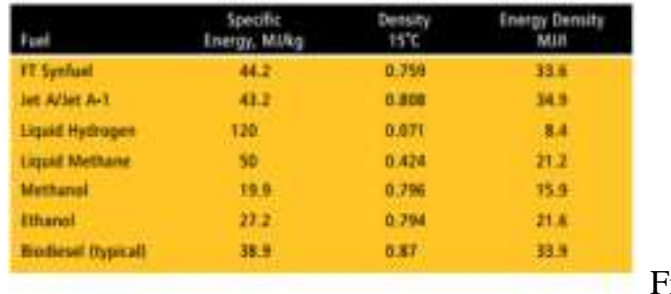

g. 2 (Greg Hemighaus, 2006)

Alternative fuels have to be examined by their ability to perform all the functions that are being carried out by conventional fuels. Fuel must be thermally stable to absorb excess heat from the engine and not degrade (Greg Hemighaus, 2006). Fuels with poor thermal stability will leave deposits in engine fuel system, which will degrade performance and will require more maintenance. Any alternate fuel for the current aircraft is to be compatible with all the materials found in aircraft systems including various metals, epoxy type coatings and elastomeric seals (Greg Hemighaus, 2006).

Majority of the jet fuels are deeply refined extractions from petroleum. Relatively small percentage is made from oil sands. There are other fossil fuel sources that can potentially be used to extract jet fuel namely, natural gas, shale oil and coal. The total energy content of fossil fuel is estimated to be larger than that of petroleum (Greg Hemighaus, 2006). Biodiesel is a bio-derived jet fuel and is being considered as an alternative source for aviation fuel. Biodiesel covers variety of materials made from vegetable oil or animal fats. (1) Various crops are used in different parts of the world to make biodiesel. (2) It is environmentally friendly and contains essentially no sulphur or aromatics. (3) It has good lubricity properties while the gravimetric energy content of biodiesel is also lower than that of jet fuel. (4) Moreover, it uses cultivation of agricultural land to produce large amounts of biodiesel thereby, helping the farmers to grow crops for their livelihood (Greg Hemighaus, 2006).

Several studies have shown that using agricultural land for producing biofuel feedstock can reduce GHS emissions. Plants like algae can be grown in these settings and are under investigation to use as feedstock (Anon., 2009). Charlie Miller, VicePresident, International Corporate Communication at Boeing, says that the best biofuels for aircrafts are algae, Jatropha, halophytes, and camelina. Algae can produce all the biofuel needed for all planes if grown in a water mass. Halophytes can grow in salty condition and the biofuels used till now have better performance than fossil fuels (Miller, 2009). He states that, the fuel efficiency of biofuels is more and hence the cost benefit can be passed on to the consumer.

Halophytes are seen as alternative to glycophyte fuel sources with the conflicts of energy, water and food of the earth land mass for approximately $43 \%$ is arid or semi-arid and $97 \%$ of the earth's water is sea water. Halophytes are salt-tolerant plants that can prosper in sea water or brackish waters and are currently common feedstocks for fuel and food in depressed countries. Benefits of halophytes agriculture include freeing up arable land and fresh water resources, cleansing the environment, decontaminating soils, desalinating brackish waters and carbon sequestration. Benefits include availability of nutrients along with ample water and sunlight. The challenges faced during halophyte cultivation are pumping and draining the required high volumes of irrigation water from sea or ocean sources, and all lands may not be suitable for crops. Challenges also include storms, transport, and diffuse harvesting. Careful attention to the use of saline agricultural fuel feed stocks are required to prevent anthropogenic disasters. Based on the test plot data it could supply 421.4 quad or $94 \% 2004$ world energy consumption with major impact on the conflicts of glycophytes. (Hendricks, n.d.)

As a work of phase 1 of this paper, MATLAB coding work done by (Roman, 2013)is taken as a reference to study the efficiency of the algae with ……ntional fuel of jet engine. The graph obtained $101 \mathrm{~d}$ that the efficiency is better compared to the 
jet fuel and from our works, we found that algae is the world's fastest growing photosynthetic organism. It is economical, renewable, environmentally friendly and easy to attain. Algae yields more energy (30time per acre, some of them even up to 15000 gallons per acre.) The major advantage of algae is that the biomass of algae can be doubled every 8-12 hours and they produce oil all the year round unlike most seasonal crops.

\section{Methodology}

MATLAB software is used in this research to compare the efficiencies of turbine using different fuels. The main comparison is between halophytic algae and jet fuel. Standard turbojet engine specifications are considered here. The calorific value of halophytic algae is found as $3963000 \mathrm{j} / \mathrm{kg}$ (John J Milledge, 2014).

The basic requirements required for evaluating a turbojet engine is researched and created a logical code for finding efficiencies in various aspects. The below-given conditions are the desired features for a turbo jet engine.

- $\quad$ Altitude of $37000 \mathrm{ft}$.

- The pressure ratio across the compressor $\pi_{\mathrm{c}}$.

- $\quad$ The Mach number $\mathrm{M}_{0}=2.0$.

- Maximum enthalpy ratio $\tau_{\lambda}=7.0$

- Fuel type is hydrocarbon with $\mathrm{QR}=$ $42800 \mathrm{~kJ} / \mathrm{kg}$

The QR (calorific value) mentioned above has been changed for halophytic algae and jet fuel in order to obtain the results for both the cases.

Similarly, to maintain engineering requirements the engine is operated as mentioned in the above conditions and did not violate any fluid mechanics or thermodynamic laws.

Turbojet engine inlet condition i.e. pressure and temperature are calculated by using below equations.

$\mathrm{P}_{\mathrm{t} 0}=\mathrm{P}_{0} *\left(1+\left(\frac{K_{C}-1}{2} * M_{0}^{2}\right)^{k_{C}} / k_{C}-1\right)$

$\mathrm{T}_{\mathrm{t} 0}=\mathrm{T}_{0} *\left(\frac{K_{C}-1}{2} * M_{0}^{2}\right)$

The military standard aircraft model 5008B is taken as a reference for inlet diffuser in this case.

$\mathrm{PID}=\mathrm{PID}_{\max } * \mathrm{n}_{\mathrm{r}} \quad\left(\right.$ where $\left.\mathrm{n}_{\mathrm{r}}=1-0.075 *\left(\mathrm{M}_{0}-1\right)^{1.35}\right)$

The air that is successfully compressed in the turbojet is defined by the percentage of compressor efficiency obtained, where it is given by the equation.

$$
\mathrm{N}_{\mathrm{c}=} \frac{\left(\mathrm{PIC}^{k_{C}} / k_{C}-1\right)}{\mathrm{Ta} 0 \mathrm{C}-1}
$$

The complete combustion of the fuel is given by the (Air-Fuel Ratio)

$$
\mathrm{f}=\frac{(\text { TaoA- }-(\text { TaoR } * \text { TaoC }))}{\left(\left(\left(\mathrm{QR} \cdot{ }^{\mathrm{nb}}\right) \cdot / \mathrm{h} 0\right)-\mathrm{TaoA}\right)}
$$

The adiabatic efficiency of the turbine is taken as

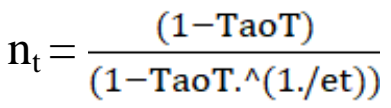

The power generated by the compressor and the turbine is calculated by the equations:

$$
\begin{aligned}
& \mathrm{P}_{\mathrm{t}}=\mathrm{m}_{\mathrm{o}} *(1+\mathrm{f}) * \mathrm{C}_{\mathrm{ph}} *\left(\mathrm{~T}_{\mathrm{t} 4}-\mathrm{T}_{\mathrm{t} 5}\right) \\
& \mathrm{P}_{\mathrm{c}}=\mathrm{P}_{\mathrm{t}} * \mathrm{n}_{\mathrm{m}}
\end{aligned}
$$

The performance of the turbine can be evaluated by

Ram Drag, $\mathrm{RD}=\mathrm{m} 0 . * \mathrm{~V} 0$

Gross Thrust, GT $=(\mathrm{m} 0+\mathrm{mf}) . * \mathrm{~V} 9$

Uninstalled Thrust, F = GT-RD

Thrust Specific fuel, TSFC $=\mathrm{mf} . / \mathrm{F}$

Finally, the efficiency of the engine is identified by Overall efficiency and Propulsive efficiency:

$$
\begin{aligned}
& \mathrm{n}_{0}=\left(\mathrm{F}^{*} \mathrm{~V} 0\right) /\left(\mathrm{mf}^{*} \mathrm{QR}\right) \\
& \mathrm{n}_{\mathrm{p}}=2 /(1+(\mathrm{V} 9 / \mathrm{V} 0))
\end{aligned}
$$

\section{Result and Discussion}

As discussed, from the above MATLAB code, the results are obtained for thrust, thermal efficiency and propulsive efficiency with changes in compression ratio. Different graphs are obtained representing jet fuel performance and halophytic fuel performance, which is done by changing calorific values in the MATLAB code. Similarly, the graphs are 
obtained.

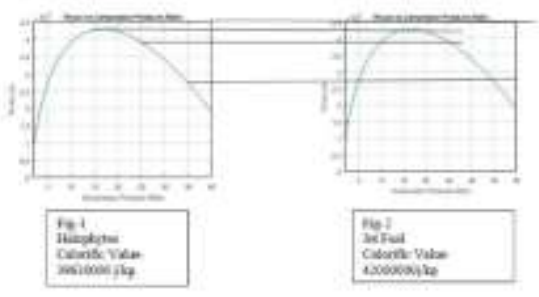

Fig. 3

The below Fig. 3 are the results obtained for the jet engine coding while input variation given was calorific value. From the figures it is observed that, the thrust value for halophytes is slightly greater than that of jet fuel and also it is noticed that as calorific value decreases there is an increase in thrust obtained.

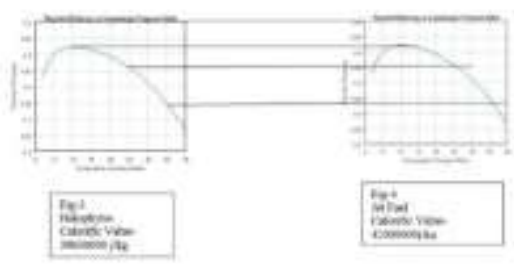

Fig. 4

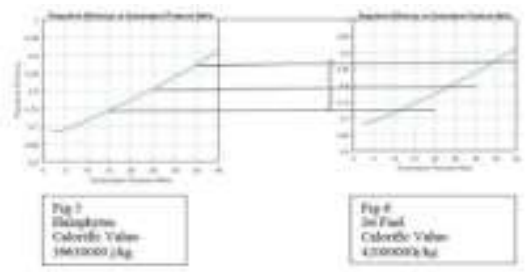

Fig. 5

The plot of thermal efficiency and propeller efficiency $\mathrm{v} / \mathrm{s}$ compressor ratio of halophytes and jet fuel (Fig. 4 and Fig. 5) are shown. Even here the values obtained are slightly higher in halophytes when compared to jet fuel and they are as shown above.

\section{Conclusion}

It is imperative that bio-fuels should replace the conventional fuels in near future. The performance of biofuels with respect to conventional fuels is studied with the help of MATLAB code. Respective calorific values of conventional fuel \& biofuel are used in the MATLAB code to obtain performance plots. From these graphs, it can be seen that there is a small difference in their performance with biofuel having a upper hand over conventional fuels.

\section{Future work}

The future work will be the continuation of this study made with references and theoretical knowledge obtained. The adaptability and cultivation of algae is not difficult as they can grow anywhere there is sunlight and water, areas that are too dry, too cold or too hot. Desert and oceans are obvious places for algae formation. Though its cultivation is easy it has certain challenges such as the mechanism of harvesting algae, conversion of algal oil to biodiesel and risk of virus contamination. Taking into account all these pros and cons, two ideas are proposed. The first idea is to build a photo (Anon., 2015) bio reactor and grow algae by varying the feed (bio-waste) while the other idea suggests breeding algae in an enclosed bag suspended in sea with provisions for supplying bio-waste. This is similar to the method used by NASA where algae is bred in a semi permeable bag suspended in sea. (Anon., 2014)

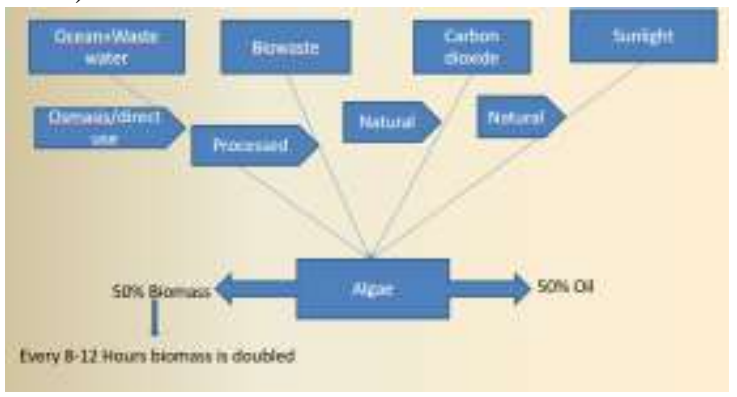

Fig. 6

\section{Acknowledgement}

This research was partially supported by Brunel University London. We are thankful to our family and friends who had been a great support and who provided expertise that greatly assisted the research.

\section{References}

[1] Anon., 2009. Algae used in biofuel on U.S. Jet Flights. [Online]

Available at:

http://www.nbcnews.com/id/285471 91/ns/us news-environment/t/algaeused-biofuel-us-jet-test-

flight/\#.WYmjU4iGNPZ

[Accessed 07 September 2017].

[2] Anon., 2015. United States Aviation green House Emissions Reduction Plan. [Online] 
Available at:

https://www.icao.int/environmental-

protection/Lists/ActionPlan/Attachme

nts/30/UnitedStates Action Plan-

2015.pdf

[Accessed 06 August 2017].

[3] Anon., n.d. Biofuel.org.uk. [Online]

Available at:

http://biofuel.org.uk/aviation-

biofuel.html

[Accessed 07 Septemeber 2017].

[4] Greg Hemighaus, T. B. B. R. O. J. L. R.

B. T. T. J. L. a. J. J., 2006. Alternative

Jet Fuels. [Online]

Available at:

https://www.cgabusinessdesk.com/d ocument/5719 Aviation Addendum.

webpdf.pdf

[Accessed 07 September 2017].

[5] Hendricks, R., n.d. Alternate-Fueled

Flight: Halophytes, Algae. National

Aeronautics and Space Admin, p. 23.

[6] John J Milledge, B. S. ,. P. W. D. a. P.

H., 2014. Macroalgae-Derived Biofuel:

A Review of Methods of Energy

Extraction from Seaweed Biomass.

energies, 7(11), p. 29.

[7] John, S., 2006. Green flights: Airlines go for biofuels. To counter the fluctuating ATF prices, this alternative source can bring a revolution in aviation, Delhi: The Times Of India .

[8] Miller, C., 2009. Green flights. 'Airlines go for biofuels'. 26 November.

[9] Roman, C. J. G., 2013.

https://www.slideshare.net/CarlosJGu tierrez/proyecto-propulsion-

30605031. [Online]. 